\title{
To screencast or not to screencast
}
D. F. Mullamphy ${ }^{1}$
P. J. Higgins ${ }^{2}$
S. R. Belward ${ }^{3}$
L. M. Ward ${ }^{4}$

(Received 2 February 2010; revised 9 June 2010)

\begin{abstract}
As the type of student entering university changes, we are obliged as educators to adapt our teaching styles to suit the new demographic. With many students unable to physically attend lectures and with the internet being accessible to the vast majority of students, the need for flexibility has become paramount. In a direct response to this need, mathematics lecturers at James Cook University created screencasts for a number of their subjects, both as lecture replacement and as supplement. These screencasts involve screen and audio capture of handwritten, typed or powerpoint lectures created using a tablet computer. This article discusses student opinion on the effectiveness of the screencasts used in teaching mathematics at James Cook University. Examining the students responses to this relatively new technology raises questions on the viability of the traditional face to face lecture and the role academics will play in a technology driven tertiary sector.
\end{abstract}

http://anziamj . austms.org.au/ojs/index.php/ANZIAMJ/article/view/2657 gives this article, (c) Austral. Mathematical Soc. 2010. Published June 30, 2010. ISSN 1446-8735. (Print two pages per sheet of paper.) 


\section{Contents}

1 Introduction

C447

2 Benefits of screencasting

C448

3 Creating the screencasts

C451

4 The survey

C453

5 Potential problems

C455

6 Conclusion

C456

References

C457

\section{Introduction}

According to the James Cook University (JCU) document "First Year Experience Questionnaire 2006 Data", 38\% of students rely on part-time or casual work as their main source of income [7]. This is not unique to regional universities with the Australian Universities Finance Report [8] stating that $35 \%$ of full time students work at least 13 hours per week while $42 \%$ of part time students work at least 38 hours per week. This has a direct impact on the students' ability to attend all of their classes, and hence they demand more flexibility in the way lectures and support materials are delivered. The modern tertiary sector is customer driven and generation Y students of today demand a service that must meet their needs. Current students are also considerably more techno-savvy than their predecessors with $70 \%$ of students at JCU frequently using the web for study [7]. This perceived need for the use of technology in the teaching of tertiary mathematics has become a source of many publications $[6,10]$. In Spain, Juan [9] discussed the lack of motivation 
for students studying mathematics in disciplines such as Business and Computer Sciences and how "the use of software based activities ... can enhance students motivation for these subjects". Hence the days of lecture courses being taught as only "chalk and talk" sessions are numbered and the push into web-based education is being driven by student demand. The Internet is becoming a necessity for students who have difficulty attending formal lectures or those who find it difficult to study during normal work-hours. With $92 \%$ of students using web-based materials on a weekly basis [7] it is very clear that this is an area that requires the utmost attention.

If we are to correct our current problems with enrollments and retention with a considerably more discerning student body than in previous years, we must engage them using appropriate media and provide the best possible service for these students. This view is supported by the 2007 report, Mathematics for 21st Century Engineering Students [2], which recognises the need for the use of technology to address the changing student cohort:

Increased accessibility of teaching and learning resources available to students at times convenient to them appears to be seen by many as one effective way of helping to address the changing needs of the student body.

The use of online materials has already changed the way many university courses are taught and access to tablet computers has the potential to make even more dramatic changes in the teaching of mathematics. Although our work is not the first to incorporate tablet technology in the teaching of mathematics $[11,13]$ it still remains a relatively new area which requires substantial attention.

\section{Benefits of screencasting}

We discuss and analyse the use of screencasting as a strategy implemented in an attempt to engage student learning. Students demand the ability to access 
materials from outside the university and at seemingly unusual times. This need can only realistically be achieved by extensive use of electronic teaching materials via the internet. The use of these electronic materials has become commonplace throughout many tertiary institutions throughout the world including Australia, New Zealand, Europe and the United States [1, 3, 12]. With the increased accessibility to tablet technology the use of screencasting as an online teaching resource will soon become standard at most universities around the world. Winterbottom [14] stated

Screencasting and podcasting are increasingly being used within a Higher Education setting to deliver a range of educational material. In the Us, many universities, including Yale and Princeton, are podcasting their public lecture series, while institutions such as Stanford and UC Berkeley are podcasting lectures from a range of modules. In the UK, the University of Wales, Aberystwyth, was the first University in the UK to create podcasts of its lectures

Screencasting within Australia still appears to be in its early stages although videos of full lectures have existed for decades. In 2007, Clarke and Taylor [4] published a study on the use of podcasts as lecture reinforcement at the University of Sydney. They stated

Almost two thirds of the students liked the fact that they could be supported to learn in their own time, supporting the 'anywhere anytime, at any pace' dictum commonly associated with podcasting and other means of flexible delivery.

Many of the perceived benefits associated with podcasting also hold for the use of screencasts and the creation of these videos has numerous benefits for both students and staff. The use of these new technologies may also provide a solution to maintaining a mathematics major at some of the smaller universities. Although this solution may seem inadequate it still provides a number of benefits for the students including

- Greater flexibility and access, 
- Material can be viewed on computers, iPods and mobile phones,

- Accessible at any time from any internet connection,

- Material can be paused, rewound and reviewed multiple times,

- Students engage better with familiar technology.

As academics are constantly under pressure to increase research and maintain student numbers, it has become necessary to maximise the benefit from the limited teaching time and resources that are available. Technology appears to be the only viable option to providing better support material for the students whilst reducing the overall workload of the academic. Some of the benefits for the lecturer include

- Minimising tedious repetition of explanations by lecturers,

- Additional screencast material and theory can be tailored for high achievers,

- Numerous examples can be created for reinforcement or can be made discipline specific,

- Providing resources digitally offers the opportunity to track which students are accessing the materials, so participation can be monitored,

- Materials can be reused for a number of years.

In addition to these benefits, screencasting may provide an alternative pathway for maintaining majors in mathematics at some of the smaller universities. Some mathematics departments are struggling to provide a mathematics major with the decreasing number of students in third year classes as well as an ever decreasing staff profile. Some universities, such as JCU, have provided a 'band aid' solution by only offering second and third year mathematics subjects in alternate years. This is far from ideal as students who fail a subject must wait two years for it to be repeated. However, with screencasting, entire online courses can be created to cover subjects not offered in that year allowing students to graduate earlier. This process may also be used to increase choice 
in third year mathematics subjects at universities where staff and student numbers are limited. Eventually, if staff numbers fall further, this may be the only way to provide students with enough subjects to maintain a mathematics major. However, the success of this approach would almost certainly rely on some form of local tutorial support.

\section{Creating the screencasts}

A large number of the issues and concepts taught in mathematics are presented visually and dynamically, working and talking through the processes. This process requires more than just text, animated PowerPoint or standard audio podcasting. With screencasting, it is possible to clearly record the lecturer's writing and annotations made with a graphics tablet, along with a clear voiceover explaining each step in the process. In an environment where student engagement is vital, this presentation format is considerably more engaging for students than the use of chalk, PowerPoint or audio-only podcasts.

In late 2007 a group of mathematics and IT lecturers at JCU obtained a grant of $\$ 30,000$ to pursue the screencasting of mathematics and IT subjects. Tablet computers were purchased as well as a number of external tablets, microphones and recording software. Initially a room was dedicated to recording lectures but, with the purchase of headset microphones, reasonable quality recordings could be made in the lecturer's own office. Using the screencapture program Camtasia, lecturers were able to create a library of video lectures for five subjects. These screencasts go well beyond the simple video or audio recording of a class. Through the use of a mixture of PowerPoint, a graphics tablet, audio and video, lectures and support materials were produced. The use of the 'talking head' in the corner of the screencast was optional and only used by one of the lectures involved. There is still debate between the lecturers involved as to whether it made the lecture more personal or was simply an unnecessary distraction. These materials were uploaded onto the internet and 
hence could be accessed from almost anywhere and viewed as many times as required. This increased flexibility allowed students to view materials in their own time and at their own pace.

As the lecturers involved in creating the screencasts were familiarising themselves with this new technology, the lecture materials created were used in a variety of different ways:

- Lectures for the entire course were replaced by high quality sound and video screencasts and tutorials were used to reinforce the material;

- Screencasts were only created as support material, such as worked examples, and face to face lectures were still given in their standard form;

- Screencasts were created to replace some lectures as well as additional support materials.

The videos varied in length from 15 to 60 minutes with anecdotal evidence indicating that 20-25 minutes was the optimum length. The videos can be created in many different formats with the most common being flash and mp4, which are suitable for the internet and iPod respectively. The files are typically 5-10 megabytes in size and can easily be downloaded on most broadband connections. To ensure that the students completing the survey had viewed at least one screencast, three lectures were replaced entirely by videos, giving students a strong incentive to access the lecture material. Once these online materials are produced they should remain useful for a number of years and are a valuable part of our online support for students who have difficulty attending formal lectures or those that require revision work. Although videos of lectures, with 'learning facilitators' have existed for decades the improvements in technology have allowed the overall product to be of a much higher standard. 


\section{The survey}

The group surveyed in this paper were presented with screencasts that were a mixture of both lecture and tutorial material. The survey was comprised of nine multiple choice and three open response questions. To ensure anonymity of respondents the survey was posted on an external site and the results were downloaded after one month. Although there were nine multiple choice questions the primary questions of interest were

- How do you rate the usefulness of screencasts as a learning resource?

- Do you think screencasts should be used as a supplement to lectures?

- Do you think that replacing lectures with a screencast was a better learning experience?

Students were also asked about how many screencasts they downloaded? where they were downloaded? how often the files were viewed? and their overall video and audio quality? Finally students were given the opportunity to provide feedback on the positive and negative aspects of the screencasts and a section was included for any additional comments. The survey was voluntary and there were 55 respondents which represents $33 \%$ of the total class.

Overall the results were very favourable with $68.5 \%$ of students responding that they were an extremely useful learning tool and a further $29.6 \%$ responding that they were quite useful (see Figure 1). This is a very positive result as less than $1 \%$ of the respondents felt that the screencasts were of little or no use. These results were similar to those obtained for the podcasting survey conducted by Clark [4] in 2007 where $66 \%$ of respondents agreed that podcasting supported or enhanced their learning. Flexibility was seen as a major benefit and this was evident in the fact that $70 \%$ of students downloaded the screencast from home and $74 \%$ of students watched them multiple times. Many students also commented that they were able to concentrate specifically on the sections of the course which they were finding more difficult and were 


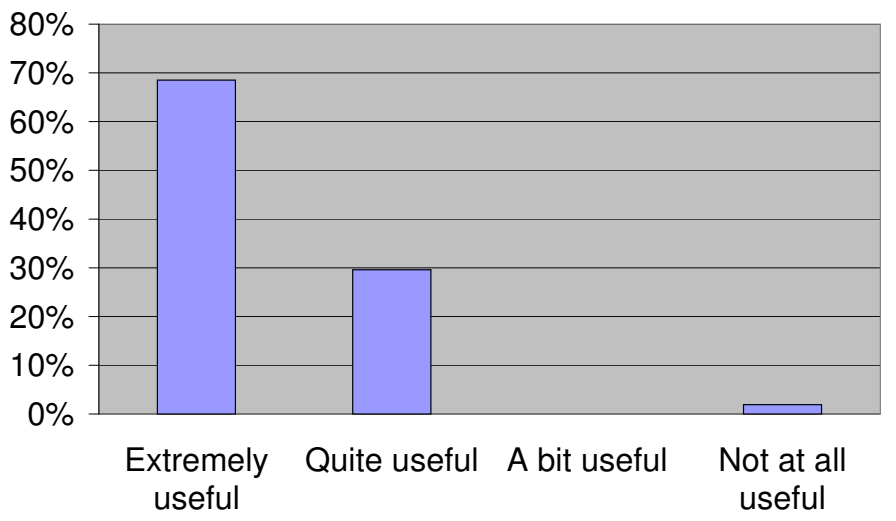

FiguRE 1: How would you rate the usefulness of screencasts as a learning resource?

able to progress through these sections at a speed that was more suitable to their own ability. Overall $87 \%$ of students found that they should be used as a supplement for lectures but only $39 \%$ believed that they should be used for lecture replacement. This was not surprising as anecdotal evidence supported the view that some of the more difficult concepts were hard to explain via the screencast and many students still require immediate interaction with the lecturer. This point was also heavily supported in the written comments where many students stated that the most negative aspect was the loss of interaction and the inability to obtain immediate clarification.

The written comments were generally very positive and concentrated on the flexibility and usefulness of the screencasts. Students also enjoyed the opportunity to view additional theory and worked examples as well as the ability to pause or rewind. An indicative set of responses are

- "Extremely effective."

- "I think the best thing about screencasts is that you can pause and rewind."

- "Great option to understand the content at one's own pace." 
- "I feel ripped off! If I wanted a degree online, I would have chosen a degree by distance."

The use of screencasts for revision was also a common theme throughout the written comments. A number of students commented that, as lectures were not on the same day as tutorials, they would forget the theory before the tutorial session. These same students also commented that screencasts help to bridge the gap between the theory in lectures and the applications in tutorials. These results are also consistent with podcasting survey results obtained by Clark [4] where a large proportion of the students surveyed stated that they used the podcasts for reinforcement. Not all students learn at the same speed and many students commented that they appreciated the ability to view materials at their own leisure. The written responses also reinforced this with over two thirds of the responses specifically praising the ability to pause and rewind sections of the video.

\section{$5 \quad$ Potential problems}

Whilst the vast majority of comments received were positive there are still some potential downsides to screencasting. These downsides include the potential for a decrease in attendance at tutorials and lectures which, besides the loss of the staff student relationship, may not be a major issue but may simply be 'flexible delivery' in action. The migration of students to other higher profile online universities remains a small concern and the fear amongst academics that the production of high quality online lectures will eventually lead to the loss of jobs in the tertiary sector remains a subject of debate.

Attendance at mathematics lectures and tutorials is often a problem and most staff believe that attendance at tutorials is vital as it is one of the rare occasions where staff get to work one on one with students. Without this personal interaction it is very difficult for lecturers to get to know their students and gauge any problems that they may be having. There is a strong 
belief amongst academics at JCU that the introduction of screencasts may lead to a further decline in attendance at both lectures and tutorials. This concern among academics is not isolated to JCU and Elliot [5] released a study in 2009 which discusses similar concerns raised in the use of podcasts at the University of South Australia. As this technology is still in its early stages it is difficult to assess the real ramifications of introducing screencasts until it has been in use for a number of years.

Staffing numbers in mathematics departments have been dwindling over the last 20 years. In order to produce a reasonable quality degree with limited staff, academics have been forced to become more creative in their delivery of subject materials. Over the last ten years JCU mathematics lecturers have created electronic lecture notes, tutorial questions, worked solutions and online quizzes. With this increased flexibility students have been able to obtain all materials online, but must attend lectures to receive detailed explanations of the lecture material. However, with the introduction of screencasts of lecture material, there appears to be less incentive for students to physically attend. Hence, once these screencasts have been made, the lecturer could easily be seen to be of minimal value and could be replaced by a part time tutor. Furthermore, if the student does not physically attend university and accesses all materials online then this is equivalent to distance education. If this is the case, then students may choose to bypass our own universities and simply choose to complete their degree at one of the many universities around the world. As stated earlier, this is still an area of great debate and requires further investigation to determine whether the use of screencasts as lecture replacement results in the loss of student enrollments.

\section{Conclusion}

The increased use of technology in tertiary teaching cannot be avoided. The modern student is techno savvy and demands flexibility and, in a climate where universities are driven by student enrollments, we have little choice but 
to deliver this flexibility. Although many universities supply a large amount of online materials such as lecture notes and tutorials, there is still a need for more substantial visually engaging online support. After experimenting with screencasting for two years, we feel that the overall response by both staff and students to the use of this technology was very positive. Increased flexibility is clearly the greatest benefit for those involved and the creation of the screencasts, though time intensive, should produce materials which will remain useful for a number of years. The ability to access high quality video explanations from almost anywhere and view them on a number of common devices is extremely useful. The multiple choice and written sections of the survey heavily support anecdotal evidence that screencasts are well received by students, and these results appear to be consistent with other recent surveys conducted at other institutions on podcasting. Although there is a belief among lecturers that their jobs are at risk from increased flexibility, we have found no hard evidence to support this view. The majority of students do not want lectures fully replaced by screencasts and saw their greatest value as a supplement to lecture materials. The increased flexibility for students, their willingness to embrace technology, the saving of time for lecturers and the ability to provide greater subject choices, all indicate that screencasting will be around for a number of years to come.

Although a significant amount of work has been done on screencasting at JCU and many other universities there is still a large body of work to complete. It is our aim, over the near future, to create a library of screencasts to cover most mathematics subjects, create discipline specific examples in our mainstream service subjects and create alternative subjects at higher year levels with additional tutorial support to offer genuine choice to our students.

\section{References}

[1] P. Bonnington, G, Oates, S. Parnell, J. Paterson and W, Stratton, A report on the use of tablet technology and screen recording software in 
tertiary mathematics courses, 2007. http://www. bonnington.org/ publications/TabletLectureRecording.pdf C449

[2] P. Broadbridge and S. Henderson, Mathematics for 21st century engineering students. 2008. http://www.altc.edu.au/ project-mathematics-21st-century-melbourne-2006 C448

[3] S. Budgett,J. Cumming and C. Miller, 2007, The role of screen recording in statistics courses. Paper presented at the 2007 International Statistical Institute conference (Lisbon). http://www. stat .auckland. ac.nz/ iase/publications/isi56/CPM82_Budgett.pdf C449

[4] S. Clark, and L. Taylor, Using short podcasts to reinforce lectures, Proceedings of the 2007 National Uniserve Science Conference, Sydney http://science.uniserve.edu.au/pubs/procs/2007/08.pdf C449, C453, C455

[5] E. Elliot, S. King and S. Cutter, To podcast or not to podcast? Pedagogical decision making in the use of new technologies, Proceedings of the 2007 National Uniserve Science Conference, Sydney http://science.uniserve.edu.au/images/content/2009_papers/ elliot1.pdf C456

[6] P. Galbraith, Students, mathematics, and technology: assessing the present - challenging the future, International Journal of Mathematical Education in Science and Technology, 7, No. 3, 2006, 277-290. doi:10.1080/00207390500321936 C447

[7] JCU First Year Experience Questionnaire 2008, http://www.jcu.edu.au/teaching/fye/index.htm C447, C448

[8] R. James, E. Bexley, M. Devlin and S. Marginson, Australian University Student Finances 2006, 2007.

http://www . universitiesaustralia.edu.au/documents/ publications/policy/survey/AUSF-Final-Report-2006.pdf C447 
[9] A. Juan, A. Huertas, C. Steegman, C. Corcoles and K. Hourigan, Mathematical e-learning: state of the art and experiences at the Open University of Catalonia, International Journal of Mathematical Education in Science and Technology, 39, No. 4, 2008, 455-471. doi:10.1080/00207390701867497 C447

[10] Q. Li. Infusing technology into a mathematics methods course: any impact?. Educational Research, 2, p.217, 2005. doi:10.1080/00131880500104341 C447

[11] B. Loch, and D. Donovan, Progressive Teaching of Mathematics with Tablet Technology, Progressive Teaching of Mathematics with Tablet Technology, 9, No. 2, 2006.

http://www.usq.edu.au/electpub/e-jist/docs/vol9_no2/papers/ current_practice/loch_donovan.htm C448

[12] E. Peterson, Incorporating Screencasts into Online Teaching, The International Review of Research in Open and Distance learning, 8, No. 3, 2007, ISSN:1492-3831. http://www. irrodl.org/index.php/ irrodl/article/viewArticle/495/935 C449

[13] M. Loomes, A. Shafarenko, and M. Loomes, Teaching mathematical explanation through audiographic technology, Computers and Education, 38, 2002, 137-149. doi:10.1016/S0360-1315(01)00083-5 C448

[14] S. Winterbottom, Virtual Lecturing; Delivering lectures using screencasting and podcasting technologies, Planet, No. 18, 2007. C449

\section{Author addresses}

1. D. F. Mullamphy, School of Engineering and Physical Sciences, James Cook University, Townsville, Australia. mailto:darcy . mullamphy@jcu.edu . au 
2. P. J. Higgins, School of Engineering and Physical Sciences, James Cook University, Townsville, Australia. mailto:patrick.higgins@jcu.edu.au

3. S. R. Belward, School of Engineering and Physical Sciences, James Cook University, Townsville, Australia. mailto:shaun. belward@jcu.edu.au

4. L. M. Ward, School of Business, James Cook University, Townsville, Australia.

mailto:lindsay.ward@jcu.edu.au 